\title{
Equilibrium Sampling of Freely Dissolved Alkylphenols into a Thin Film of 1-Octanol Supported on a Hollow Fiber Membrane
}

\author{
Jing-fu Liu, † Xia-lin Hu,† Jin-feng Peng, † Jan Åke Jönsson,‡ Philipp Mayer,§ and Gui-bin Jiang*,† \\ State Key Laboratory of Environmental Chemistry and Ecotoxicology, Research Center for Eco-Environmental Sciences, \\ Chinese Academy of Sciences, P.O. Box 2871, Beijing 100085, China, Department of Analytical Chemistry, Lund University, \\ P.O. Box 124, S-221 00 Lund, Sweden, and National Environmental Research Institute, P.O. Box 358, \\ 4000 Roskilde, Denmark
}

A new negligible depletion extraction procedure was proposed for equilibrium sampling of 4-tert-octylphenol (OP) and 4-nonylphenol (NP) into a thin film of 1-octanol supported on a hollow fiber membrane. This thin liquid film extraction technique was directed at the determination of (1) freely dissolved concentrations, (2) distribution coefficients to 1-octanol $\left(D_{\text {ow }}\right)$, and (3) binding to dissolved organic matter $\left(D_{\text {DOC }}\right)$. The sampling device was prepared by dipping pieces of polypropylene microporous hollow fiber membrane (10-mm length, $30-\mu \mathrm{m}$ wall thickness, $240-\mu \mathrm{m}$ inner diameter) into 1-octanol for a few seconds to impregnate the pores of the hollow fiber wall. After stirring in $100 \mathrm{~mL}$ of sample solution for $24 \mathrm{~h}$, the sampling device was harvested and desorbed with $30 \mu \mathrm{L}$ of methanol, of which $20 \mu \mathrm{L}$ was injected for HPLC analysis. With the measured $D_{\text {ow }}$ of a chemical and its equilibrium concentration in the 1-octanol sampling phase $\left(C_{\text {octanol }}\right)$, the freely dissolved concentration $\left(C_{\text {free }}\right)$ was calibrated based on $C_{\text {free }}=C_{\text {octanol }} / D_{\text {ow }}$. Measured log $D_{\text {ow }}$ values of OP (4.32 \pm 0.06$)$ and NP (4.79 \pm 0.02$)$ were independent of the chemical concentration, only minimally affected by the environmentally relevant $\mathrm{pH}$, buffering capacity, and salinity of samples, and agreed well with reported values. $\log D_{\text {DOC }}$ values of OP (4.89 $\pm 0.43)$ and NP (5.14 $\pm \mathbf{0 . 3 7})$, determined in Aldrich humic acid solution, agreed with reported partition coefficients to organic carbon $\left(\log K_{\mathrm{oc}}\right)$ for particles in river water and effluent wastewater. Short equilibration times and high enrichment factors were obtained for both analytes due to the high surface to volume ratio of the new sampler. The technique was successfully applied to determine $C_{\text {free }}$ of OP and NP in real water samples and to study their association with humic acids and bovine albumin.

The freely dissolved concentration $\left(C_{\text {free }}\right)$ of a chemical is a key parameter for its environmental fate, exposure, and effects. The freely dissolved concentration is often the effective concentra-

\footnotetext{
* To whom correspondence should be addressed. E-mail: gbjiang@rcees.ac.cn. Fax: $+86-10-62849179$.

$\dagger$ Research Center for Eco-Environmental Sciences.

¥ Lund University.

\& National Environmental Research Institute.
}

tion for uptake and toxicity in aquatic organisms, and it also controls the partitioning from water into other environmental phases. Various methods have been developed for measuring $C_{\text {free }}$ in environmental samples. ${ }^{1}$ For example, diffusion gradients in thin films (DGT), ${ }^{2}$ Donnan membrane technique ${ }^{3}$ and other methods such as permeation liquid membrane and gel-integrated microelectrode ${ }^{4,5}$ were used for sensing metals; whereas semipermeable membrane devices (SPMD) ${ }^{6}$ and solid-phase microextraction (SPME) ${ }^{7-9}$ were adopted for sampling mainly hydrophobic organic compounds. Equilibrium sampling through membranes (ESTM) with hollow fiber supported liquid membranes was recently applied for sampling of ionogenic organic compounds ${ }^{10}$ and metals. ${ }^{11}$

Sampling the freely dissolved chemicals can be conducted in dynamic or equilibrium mode. For instance, DGT and SPMD are generally operated in dynamic mode as they need long times to reach equilibrium, whereas SPME can be used as an equilibrium sampling device due to its relatively short equilibration time. ${ }^{12}$ One of the major advantages of the equilibrium sampling mode is that the calibration can be more easily conducted when field sampling is concerned, as it does not require use of dynamic parameters such as uptake rates. Therefore, development of

(1) Heringa, M. B.; Hermens, J. L. M. Trends Anal. Chem. 2003, 22, 575-587. (2) Davison, W.; Zhang, H. Nature 1994, 367, 546-548.

(3) Weng, L.; van Riemsdijk, W. H.; Temminghoff, E. J. F. Anal. Chem. 2005 , 77, 2852-2861.

(4) Van Leeuwen, H. P.; Town, R. M.; Buffle, J.; Cleven, R. F. M. J.; Davison, W.; Puy, J.; Van Riemsdijk, W. H.; Sigg, L. Environ. Sci. Technol. 2005 39, 8545-8556.

(5) Sigg, L.; Black, F.; Buffle, J.; Cao, J.; Cleven, R.; Davision, W.; Galceran, J.; Gunkel, P.;Kalis, E.; Kistler, D.; Martin, M.; Noel, S.; Nur, Y.; Odzak, N.; Puy, J.; Van Riemsdijk, W.; Temminghoff, E.; Tercier-Waeber, M.-L.; Toepperwien, S.; Town, R. M.; Unsworth, E.; Warnken, K. W.; Weng, L.; Xue, H.; Zhang, H. Environ. Sci. Technol. 2006, 40, 1934-1941.

(6) Petty, J. D.; Poulton, B. C.; Charbonneau, C. S.; Huckins, J. N.; Jones, S. B.; Cameron, J. T.; Prest, H. F. Environ. Sci. Technol. 1998, 32, 837-842.

(7) Vaes, W. H. J.; Urrestarazu Ramos, E.; Verhaar, H. J. M.; Seinen, W.; Hermens, J. L. M. Anal. Chem. 1996, 68, 4463-4467.

(8) Poerschmann, J.; Kopinke, F.-D.; Pawliszyn, J. Environ. Sci. Technol. 1997, 31, 3629-3636.

(9) Poerschmann, J.; Zhang, Z.; Kopinke, F.-D.; Pawliszyn, J. Anal. Chem. 1997, 69, 597-600.

(10) Liu, J.-F.; Jönsson, J. Å.; Mayer, P. Anal. Chem. 2005, 77, 4800-4809.

(11) Romero, R.; Liu, J.-F.; Mayer, P.; Jönsson, J. Å. Anal. Chem. 2005, 77, 76057611.

(12) Mayer, P.; Tolls, J.; Hermens, J. L. M.; Mackay, D. Environ. Sci. Technol. 2003, 37, 184A-191A.

10.1021/ac0615145 CCC: $\$ 33.50$ @ 2006 American Chemical Society Published on Web 11/10/2006 
equilibrium sampling devices that facilitate sensing of $C_{\text {free }}$ in a complex matrix is of interest. Equilibrium sampling with SPME fibers in combination with gas chromatography (GC) detection is well suited for measuring $C_{\text {free }}$ of hydrophobic compounds as analytes sampled onto the fiber can be directly desorbed at the injection port of GC. However, predesorption with solvent is performed to combine this technique with high-performance liquid chromatography (HPLC). Solvent microextraction, ${ }^{13}$ based on the suspension of a $1-\mu \mathrm{L}$ drop of $n$-octane on the tip of a microsyringe needle in an aqueous solution, can be conveniently coupled with HPLC to measure the $C_{\text {free }}$ of some polar and nonpolar organic compounds, but the solvent drop is vulnerable to physical forces. This problem of physical instability was solved in the recent work on ESTM with hollow fiber supported liquid membranes. ${ }^{10}$ The ESTM technique was successfully combined with HPLC and spectrophotometry and applied to both ionogenic organic compounds ${ }^{10}$ and metals. ${ }^{11}$ The present available modes of the ESTM technique, however, are less suited for the sampling of nonionizable hydrophobic organic compounds. Membrane-assisted liquid-phase microextraction, based on organic solvent filled in the lumen of a hollow fiber, can in principle be applied for the sampling of hydrophobic compounds. However, the relatively large solvent volume in the lumen and membrane would require very large sample volumes and long equilibration times in order to ensure equilibrium sampling under negligible analyte depletion conditions.

The aim of the present study is to present a new and simple sampling format that facilitates the equilibrium sampling of nonpolar organics into a thin solvent film with the eventual goal to facilitate and simplify (1) the determination of freely dissolved concentrations with HPLC, (2) the determination of solvent to water partition coefficient, and (3) the study of analyte binding to dissolved organic matter. The proposed method is based on the equilibrium sampling of dissolved analytes into a micrometer thin liquid membrane of 1-octanol, which is physically held by a porous polypropylene hollow fiber. The technique is termed thin liquid film extraction (TLFE) and is operated in the following way: The micropores of the polypropylene hollow fiber membranes are filled with 1-octanol, and the hollow fiber membranes are placed into the sample for an equilibrium extraction while minimizing the impact on the sample. The analytes are subsequently desorbed into methanol and then analyzed with HPLC. Finally, $C_{\text {octanol }}$ and $C_{\text {free }}$ are determined by external calibration.

4-tert-Octylphenol (OP) and 4-nonylphenol (NP), with known endocrine potential, are widely present in environmental samples. $\mathrm{NP}$ and OP in an aquatic environment are mainly degradation products of 4-nonylphenol polyethoxylates and 4-tert-octylphenol polyethoxylates, ${ }^{14}$ which are a group of nonionic surfactants that find widespread use as detergents, wetting agents, emulsifiers, and stabilizers. ${ }^{15}$ The distribution between dissolved phase and suspended solids for the river water and wastewater samples, ${ }^{16}$ as well as the sorption of NP in terrestrial soils, has been studied earlier. ${ }^{17}$ However, studies on the binding of these compounds to

(13) Jeannot, M. A.; Cantwell, F. F. Anal. Chem. 1997, 69, 2935-2940.

(14) Ahel, M.; Giger, W.; Koch, M. Water Res. 1994, 28, 1131-1142.

(15) Aboul-Kassim, T. A.; Simoneit, B. R. T. Crit. Rev. Environ. Sci. Technol. 1993, 23, 325-376.

(16) Isobe, T.; Nishiyama, H.; Nakashima, A.; Takada, H. Environ. Sci. Technol. 2001, 35, 1041-1049. dissolved organic matter (DOM) and the effect of DOM on the bioavailability of these compounds are scarce. ${ }^{18}$ For studying the binding of these compounds to DOM, methods for sensing their $C_{\text {free }}$ are needed. Here we report the application of the proposed TLFE technique for the measurement of $C_{\text {free }}$ of NP and OP and for studying their binding to DOM.

\section{EXPERIMENTAL SECTION}

Reagents and Materials. All reagents were of analytical reagent grade, and deionized water was used throughout the experiments. Individual standard stock solutions $(1000 \mu \mathrm{g} / \mathrm{mL})$ of NP and OP (Tokyo Kasei Kogyo Co. Ltd., Tokyo, Japan) were prepared in methanol, and working solutions were prepared daily by appropriate dilution of the stock solution with water. Terrestrial origin humic acid sodium salt was obtained from Acros Organics (lignite, technical, 50-60\% as humic acid; Acros Organics, Morris Plains, NJ) and Aldrich (technical, lot S15539-384, Sigma-Aldrich) and used as obtained. Bovine albumin V (BSA) was obtained from Biodee Biotechnology Co. Ltd. (Beijing, China). The DOC (measured in a solution prepared by dissolving $20 \mathrm{mg}$ in $200 \mathrm{~mL}$ of water and filtered through a $0.45-\mu \mathrm{m}$ membrane, with a Phoenix 8000 UV-persulfate TOC Analyzer, Tekmar Dohrmann) of Acros humic acid, Aldrich humic acid, and BSA was 45.0, 35.1, and 24.9\%, respectively.

LC-grade methanol and acetonitrile were purchased from Scharlau Chemie SA (Barcelona, Spain). Other chemicals such as sodium dihydrogen phosphate, sodium hydroxide, sodium chloride, and hydrochloric acid were obtained from Beijing Chemicals Corp. (Beijing, China).

The 50/280 Accurel polypropylene (PP) hollow fiber tubing (50- $\mu \mathrm{m}$ wall thickness, $280-\mu \mathrm{m}$ inner diameter, $0.1-\mu \mathrm{m}$ pore size) and X30-240 Celgard polypropylene microporous hollow fiber membrane (30- $\mu \mathrm{m}$ wall thickness, $240-\mu \mathrm{m}$ inner diameter, 0.04 $\mu \mathrm{m}$ pore size, $40 \%$ porosity) were obtained from Membrana $\mathrm{GmbH}$ (Wuppertal, Germany). Spectra/Por Biotech cellulose ester dialysis membranes (8-mm flat widths) with molecular mass cutoff (MWCO) of 1000 Da was obtained from Spectrum Laboratories Inc. (Rancho Dominguez, CA). BD Micro-Fine syringes (with a needle of $0.30-\mathrm{mm}$ outer diameter and 8-mm length, $0.5 \mathrm{~mL}$ ) were obtained from BD Consumer Healthcare and used to fill the acceptor into the lumen of the hollow fiber for extraction and to flush out the acceptor into a small glass vial (50 $\mu \mathrm{L}$, Alltech) after extraction.

HPLC Separation. The HPLC system was equipped with an Agilent 1100 Series isocratic pump (IsoPump) and an Agilent 1100 Series fluorescence detector (FLD) set at 220-nm excitation and 315-nm emission wavelengths, respectively. A personal computer equipped with an Agilent ChemStation program for the LC system was used to process chromatographic data. The separation of OP and NP was performed on an Agilent Zorbax Eclipse $\mathrm{XDB}^{-\mathrm{C}_{8}}$ column $(150 \times 4.6 \mathrm{~mm}$, particle size $5 \mu \mathrm{m})$ by using a mixture $(75: 25, \mathrm{v} / \mathrm{v})$ of acetonitrile and phosphate buffer $(0.01 \mathrm{mM}, \mathrm{pH}$ 7.0) as mobile phase at $1.0 \mathrm{~mL} / \mathrm{min}$. For quantification of the amount of analytes taken up into the sampling device, external

(17) During, R.-A.; Krahe, S.; Gath, S. Environ. Sci. Technol. 2002, 36, 40524057.

(18) Vinken, R.; Hollrigl-Rosta, A.; Schmidt, B.; Schaffer, A.; Corvini, P. F.X. Water Sci. Technol. 2004, 50, 277-283. 
calibration curves were prepared by injecting $20-\mu \mathrm{L}$ aliquots of standard solution prepared in methanol.

Preparation of the Sampling Device. The TLFE sampling device was prepared as follows: a piece of 10-mm-long hollow fiber was connected to the needle of the BD Micro-Fine syringe holding reagent water. Then the plunger of the syringe was depressed to flush out $\sim 0.1 \mathrm{~mL}$ of water to wash and fill the lumen of the hollow fiber. The fiber was dipped into the organic solvent (1-octanol) for a few seconds to impregnate the pores of the hollow fiber wall. After that, the whole fiber with filled water and impregnated organic solvent was immersed into water and shaken $\sim 1$ min to wash out surplus organic solvent.

For preparation of the dialysis tubing protected sampling device, the above prepared hollow fiber sampler was immersed in $\sim 0.1 \mathrm{~mL}$ of reagent water filled in dialysis tubing (3-cm length, 8-mm flat width, and the two ends sealed with a string).

Sampling Procedure. For sampling, the above-prepared hollow fiber sampler was put into $100 \mathrm{~mL}$ of sample solution held in a capped flask with near-zero headspace and the magnetic stirrer turned on to keep the hollow fiber sampling device completely immersed into the sample solution. After stirring for the selected time, the hollow fiber sampling device was harvested and the extracted analytes were desorbed with $30 \mu \mathrm{L}$ of methanol, of which $20 \mu \mathrm{L}$ was manually aspirated into a HPLC microsyringe and injected into the HPLC system for analysis. Standard solutions containing $50 \mu \mathrm{g} / \mathrm{L} \mathrm{OP}$ and NP were used unless otherwise stated.

Measuring the Sampling Phase Volume. The supported liquid membrane was prepared with 1-octanol that was spiked with $500 \mathrm{mg} / \mathrm{L} \mathrm{NP}$ and then directly desorbed and analyzed. The 1-octanol volume was calculated based on HPLC peak areas of the NP and a calibration curve of peak area against 1-octanol volume. To obtain the calibration curve, $1,2,3,4$, and $5 \mu \mathrm{L}$ of 1-octanol (containing $500 \mathrm{mg} / \mathrm{L} \mathrm{NP}$ ) were spiked into $30 \mu \mathrm{L}$ of methanol, respectively. Then, $20 \mu \mathrm{L}$ each of the methanol solutions was injected for HPLC analysis, and the obtained peak areas were plotted against the 1-octanol volume.

The initial volume of 1-octanol on the hollow fiber membrane and the stability of this volume during the sampling procedure were confirmed by gas chromatography/mass spectrometry (GC/ MS). The TLFE sampling device was prepared as described earlier and then put into $100 \mathrm{~mL}$ of reagent water for various sampling times. The sampling device was then harvested and desorbed with $100 \mu \mathrm{L}$ of toluene, of which $1 \mu \mathrm{L}$ was injected into the $\mathrm{GC} / \mathrm{MS}$ system for analysis. The GC/MS system was equipped with an Agilent 6890 GC, a 5973 mass-selective detector, and a DB-5MS fused-silica capillary column (film thickness, $0.25 \mu \mathrm{m} ; 30 \mathrm{~m} \times 0.25$ $\mathrm{mm}$ i.d.). The oven temperature program was set as follows: the initial temperature was held at $80^{\circ} \mathrm{C}$ for $1 \mathrm{~min}$, increased to 280 ${ }^{\circ} \mathrm{C}$ at $15{ }^{\circ} \mathrm{C} / \mathrm{min}$, and a postanalysis baking at $300{ }^{\circ} \mathrm{C}$ was applied for $3 \mathrm{~min}$. Quantification of 1-octanol was conducted by external calibration with standards prepared in toluene, and with the mass spectrometer operated in selected ion monitoring mode for detecting the characteristic ion fragments of 1-octanol $(\mathrm{m} / z=41$, 56, 70, 84).

Sample Collection. Tap water was collected after letting it flow $\sim 5 \mathrm{~min}$ in order to minimize dissolved, particulate, and gaseous impurities, and $0.1 \% \mathrm{Na}_{2} \mathrm{~S}_{2} \mathrm{O}_{3}$ was added to eliminate hypochlorite before spiking the analytes. River water was collected from the Yongding River in the suburb of Beijing. Municipal sewage effluent was collected at Gaobeidian sewage treatment works in the east part of Beijing. Wastewater was collected from Dalian, China. The river water and wastewater samples were spiked with $100 \mathrm{mg} / \mathrm{L} \mathrm{HgCl}_{2}$ to avoid biodegradation.

Data Process and Calibration. All experiments were conducted in triplicate, and the mean values were reported. Some of the experimental data were fitted to models by using Graphpad Prism (ver. 4.1, GraphPad Software, San Diego, CA). Assuming the partitioning to the sampling phase is linear, the uptake profile of analytes can be fitted to a first-order one-compartment uptake model modified from ref 12

$$
C_{\text {octanol }}(t)=C_{\text {free }} D_{\text {ow }}\left(1-\mathrm{e}^{-k t}\right)=C_{\text {free }}{ }^{0} D_{\text {ow }}\left(1-\mathrm{e}^{-k t}\right)
$$

or

$$
C_{\text {octanol }} / C_{\text {free }}=D_{\text {ow }}\left(1-\mathrm{e}^{-k t}\right)
$$

where $C_{\text {octanol }}(t)$ is the analyte concentration in 1-octanol supported on the hollow fiber at time $t, C_{\text {free }}$ is the analyte concentration of sample, which can be regarded as a constant that equals to its initial concentration $\left(C_{\text {free }}{ }^{0}\right)$ in negligible depletion extraction, $k$ is the rate constant, and $D_{\mathrm{ow}}$ is the distribution coefficient between the 1-octanol (supported on the hollow fiber) and the aqueous solution.

The $C_{\text {octanol }}$ was calculated as in eq 3 , where $C$ is the

$$
C_{\text {octanol }}=\left(V_{\text {methanol }} C\right) / V_{\text {octanol }}=(30 C) / V_{\text {octanol }}
$$

concentration that was calculated from the HPLC peak area obtained by injecting $\left(V_{\text {inject }}=20 \mu \mathrm{L}\right)$ the extracted analyte desorbed from the hollow fiber with methanol $\left(V_{\text {methanol }}=30 \mu \mathrm{L}\right)$ and the external calibration curves prepared by injecting aliquots ( $V_{\text {inject }}=20 \mu \mathrm{L}$ ) of standard solution; $V_{\text {octanol }}$ is the volume of 1-octanol supported on the hollow fiber $\left(V_{\text {octanol }}=0.12\right.$ or $0.37 \mu \mathrm{L}$, measured as described in this study).

The $k$ value obtained from eq 1 can also be adopted to estimate equilibrium sampling times (e.g., $t_{90 \%}=\ln (0.10) /(-k), t_{95 \%}=$ $\ln (0.05) /(-k))$. The $D_{\text {ow }}$ value obtained from eq 1 was also used to calculate the sample depletion based on the sample volume $\left(V_{\text {sample }}\right)$ and 1-octanol volume $\left(V_{\text {octanol }}=0.12\right.$ or $\left.0.37 \mu \mathrm{L}\right)$ :

$$
\text { depletion } \%=100 D_{\mathrm{ow}} V_{\text {octanol }} / V_{\text {sample }}
$$

Experiments of this study demonstrated that $D_{\text {ow }}$ is a constant that is independent of the environmentally relevant buffer capacity, $\mathrm{pH}$, and salinity of freshwater (for seawater, the influence of salinity can be calibrated by using $D_{\text {ow }}$ measured in $500 \mathrm{mM} \mathrm{NaCl}$ solutions). Consequently, $C_{\text {free }}$ can be calibrated with the determined $D_{\text {ow }}$ and $C_{\text {octanol }}$ as follows:

$$
C_{\text {free }}=C_{\text {octanol }} / D_{\text {ow }}
$$

\section{RESULTS AND DISCUSSION}

Initial Sampling-Phase Volume and Surface to Volume Ratio. The initial volume of 1-octanol on the membranes measured 
by HLPC agreed well with GC/MS measurements and also with the stated pore volume of the respective hollow fibers. The initial 1-octanol volume on the X30-240 Celgard fiber was measured to be $0.13 \pm 0.02 \mu \mathrm{L} / \mathrm{cm}(n=6)$ by HPLC and $0.12 \pm 0.01 \mu \mathrm{L} / \mathrm{cm}$ $(n=3)$ by GC/MS. These measurements are slightly higher than the calculated pore volume of $0.10 \mu \mathrm{L} / \mathrm{cm}$ for this fiber. This is reasonable as the measured 1-octanol volume includes both that supported in the micropores and that on the surfaces of the fiber wall. The initial 1-octanol volume on the 50/280 Accurel PP was measured to be $0.40 \pm 0.03 \mu \mathrm{L} / \mathrm{cm}(n=6)$ by HPLC and $0.37 \pm$ $0.02 \mu \mathrm{L} / \mathrm{cm}(n=3)$ by GC/MS. The pore volume of the $50 / 280$ Accurel PP hollow fiber cannot be calculated as its porosity is not available, but it should be in the range of $0.26-0.36 \mu \mathrm{L} / \mathrm{cm}$, assuming a porosity in the range of $50-70 \%$.

The surface to volume ratio was calculated to be 67000 $\mathrm{m}^{2} / \mathrm{m}^{3}$ for the X30-240 Celgard membrane and $40000 \mathrm{~m}^{2} / \mathrm{m}^{3}$ for the 50/280 Accurel PP membrane. These surface to volume ratios are in the same range as for polymer-coated SPME fibers, and they are orders of magnitude higher than for most samplers that are based on the partitioning into a liquid phase. The proposed TLFE format will thus provide fast sampling kinetics and thereby facilitate the equilibrium sampling into liquid phases.

Stability of Sampling-Phase Volume. The GC/MS method was also applied to confirm the stability of the 1-octanol volume supported on the X30-240 Celgard membrane during the extraction process. The 1-octanol volume after sampling of $0,1,2,6,12$, 24 , and $48 \mathrm{~h}$ was measured to be $0.12,0.12,0.11,0.12,0.12,0.11$, and $0.11 \mu \mathrm{L} / \mathrm{cm}$, respectively. This indicates that the 1-octanol supported on 10-mm X30-240 Celgard hollow fiber membrane was stable in a $100-\mathrm{mL}$ sample during a 48 -h sampling time. 1-Octanol has an aqueous solubility of $300 \mathrm{mg} / \mathrm{L}$, and the volume of the aqueous sample would be sufficient to dissolve the entire amount of 1-octanol. The observed stability of the supported 1-octanol membrane might be attributed to the slow release of 1-octanol from the porous membrane. Further research is required in order to understand the cause of the stability of the 1-octanol film and to determine the long-term stability of the 1-octanol film under various conditions.

Desorption Time. After sampling, the extracted analytes must be desorbed from the hollow fiber for analysis by HPLC. To reach higher sensitivity and repeatability, the desorption time was optimized to ensure the complete desorption of analytes from the hollow fiber. Experimental results (see Figure S1 in Supporting Information) show that for both OP and NP the desorption was almost complete after static soaking in $30 \mu \mathrm{L}$ of methanol for 40 min. Experiments also showed that ultrasonication did not enhance the desorption of analytes. Thus, $40 \mathrm{~min}$ of static soaking in $30 \mu \mathrm{L}$ of methanol was chosen as optimum desorption condition in the following studies.

Equilibration Time. Some parameters that can influence the equilibration time were investigated in detail in order to ensure that sampling was maintained until the sampler and its surroundings have reached a thermodynamic equilibrium. During sampling, the analyte concentration in the 1-octanol sampling phase $\left(C_{\text {octano }}\right)$ typically increases with time to a constant value. As criteria that a thermodynamic equilibrium was attained, it is required that (1) the increase in $C_{\text {octanol }}$ stopped and (2) $D_{\text {ow }}=$
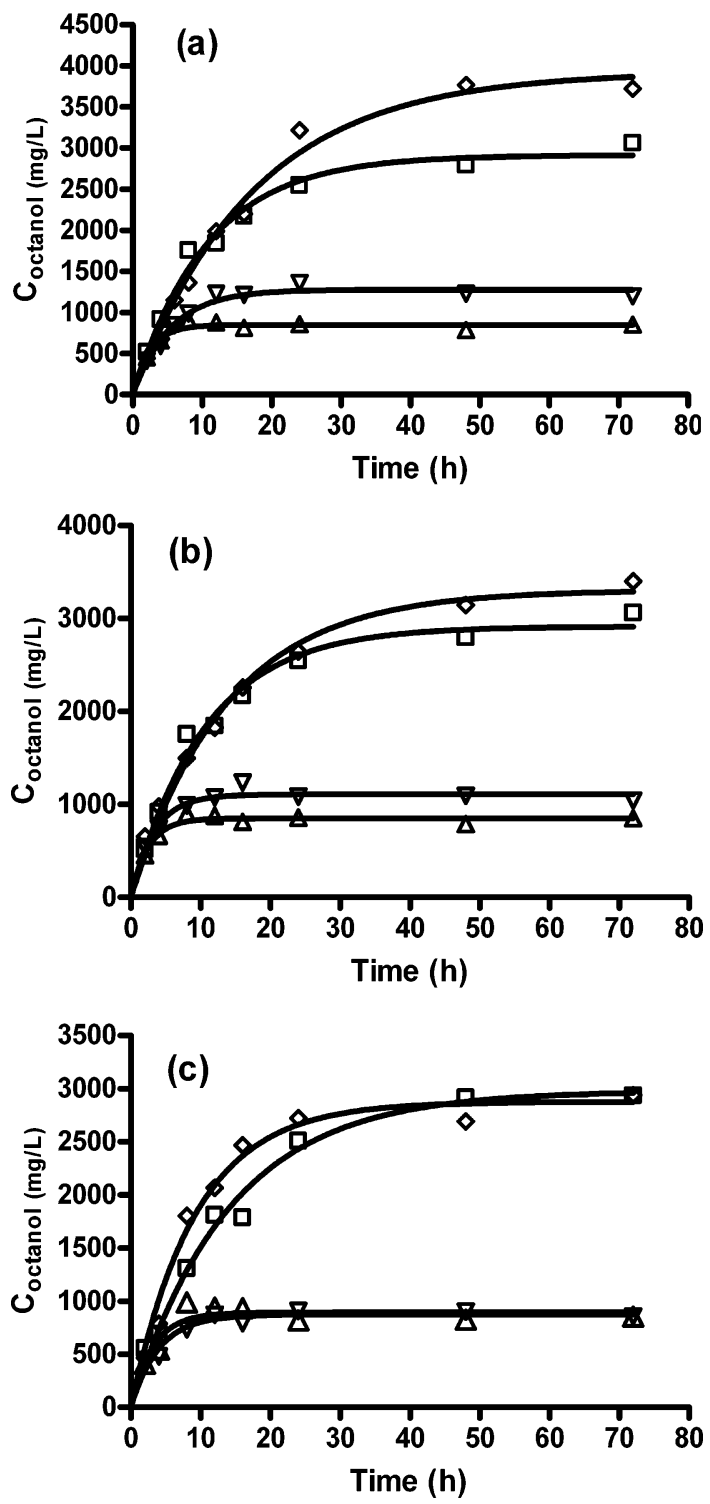

Figure 1. Influence of some environmentally relevant parameters on the equilibrium sampling time for OP and NP. The lines represent the fit of eq 1 to the data. Sample solution: $100 \mathrm{~mL}$ of $50 \mu \mathrm{g} / \mathrm{L}$ OP and NP. Sampling phase: 1-octanol supported on $5 \mathrm{~mm}$ of 50/280 Accurel PP polypropylene hollow fiber. (a) Effect of phosphate buffer concentration (pH 7.00): $\diamond, N P$ in $200 \mathrm{mM}$ buffer; $\square$, NP in $1 \mathrm{mM}$ buffer; $\nabla$, OP in $200 \mathrm{mM}$ buffer; $\triangle$, OP in $1 \mathrm{mM}$ buffer. (b) Effect of salinity $(\mathrm{pH} 7.00): \diamond, N P$ in a mixture of $1 \mathrm{mM}$ phosphate buffer and $500 \mathrm{mM} \mathrm{NaCl} ; \square, \mathrm{NP}$ in $1 \mathrm{mM}$ phosphate buffer; $\nabla$, OP in a mixture of $1 \mathrm{mM}$ phosphate buffer and $500 \mathrm{mM} \mathrm{NaCl} ; \triangle$, OP in $1 \mathrm{mM}$ phosphate buffer. (c) Effect of $\mathrm{pH}$ (30 mM phosphate buffer): $\diamond, N P$, pH 5.00; $\square, \mathrm{NP}, \mathrm{pH} 8.50 ; \nabla, \mathrm{OP}, \mathrm{pH} 5.00 ; \triangle, \mathrm{OP}, \mathrm{pH} 8.50$.

$C_{\text {octanol }} / C_{\text {free }}$ was close to the relevant partition coefficient between the 1-octanol and the aqueous solution $\left(K_{\mathrm{ow}}\right)$.

The influence of sample buffer capacity, salinity, and $\mathrm{pH}$ on equilibration time was studied using 0.5 -cm 50/280 Accurel PP hollow fiber pieces, $100 \mathrm{~mL}$ of standard solution, and under the environmentally relevant lower and upper limits, ${ }^{19}$ i.e., 1 and 200 $\mathrm{mM}$ phosphate buffer, 0 and $500 \mathrm{mM} \mathrm{NaCl}(\sim 3 \%$, corresponding to seawater), and $\mathrm{pH} 5.0$ and $\mathrm{pH} 8.5$, respectively. A $1 \mathrm{mM}$

(19) Lutzhoft, H.-C. H.; Vaes, W. H. J.; Freidig, A. P.; Halling-Sorensen, B.; Hermens, J. L. M. Environ. Sci. Technol. 2000, 34, 4989-4994. 
Table 1. Effect of Sample Matrix on the Distribution Coefficient ( $D_{o w}$ ), Uptake Rate Constant (k), Equilibration Time (t), and Sample Depletion from Different Sample Solutions (50 $\mu \mathrm{g} / \mathrm{L}$ OP and NP Spiked in Different Matrixes) to the Sampling Devices Made from X30-240 Celgard Hollow Fiber Membrane

\begin{tabular}{|c|c|c|c|c|c|c|}
\hline \multirow[b]{2}{*}{ sample matrix } & \multirow[b]{2}{*}{ compds } & \multirow[b]{2}{*}{$D_{\text {ow }}$} & \multirow[b]{2}{*}{$k\left(\mathrm{~h}^{-1}\right)$} & \multicolumn{2}{|c|}{ equilibration time (h) } & \multirow{2}{*}{$\begin{array}{c}\text { sample } \\
\text { depletion (\%) }\end{array}$} \\
\hline & & & & $t_{(90 \%)}$ & $t_{(95 \%)}$ & \\
\hline \multirow[t]{2}{*}{$200 \mathrm{mM}$ phosphate $(\mathrm{pH} 7.00)$} & $\mathrm{OP}$ & 22564 & 0.39 & 5.9 & 7.7 & 2.9 \\
\hline & NP & 73364 & 0.12 & 18.8 & 24.6 & 9.7 \\
\hline mixture of $1 \mathrm{mM}$ phosphate and & $\mathrm{OP}$ & 21402 & 0.64 & 3.6 & 4.7 & 2.8 \\
\hline $500 \mathrm{mM} \mathrm{NaCl}(\mathrm{pH} 7.00)$ & $\mathrm{NP}$ & 66197 & 0.15 & 15.0 & 19.5 & 8.6 \\
\hline
\end{tabular}

concentration of phosphate buffer was adopted to study the effect of salinity in order to avoid the salinity effect resulting from the high concentration of phosphate, while $30 \mathrm{mM}$ phosphate buffer was used to provide appropriate buffer capacity to study the effect of $\mathrm{pH}$. The uptake profiles of analytes to the 1-octanol supported on hollow fiber shown in Figure 1, as well as the calculated $D_{\text {ow }}$, $k$, and equilibration time ( $t_{90 \%}$ and $\left.t_{95 \%}\right)$ according to the fits of eq 1 (Table S1 in Supporting Information) indicate that all these studied parameters can influence the equilibration time, and significantly longer equilibration time occurred in $500 \mathrm{mM} \mathrm{NaCl}$ and $200 \mathrm{mM}$ phosphate buffer for both OP and NP. The equilibration time was shorter for OP than for NP under all tested conditions, which can be explained by the lower enrichment factor of OP. $\mathrm{pH}$ had a significant effect on the uptake kinetics into the 1-octanol film, whereas no $\mathrm{pH}$ effect was observed for the equilibrium distribution. The buffer capacity and the salinity had to the contrary a significant effect on the equilibrium distribution (Figure 1).

The organic solvent used as sampling phase can also influence the equilibration time. The equilibration time (see Figure S2 in Supporting Information) decreased dramatically to $30 \mathrm{~min}$ for OP and $120 \mathrm{~min}$ for NP when undecane was used as the sampling solvent. These equilibration times were much shorter in comparison with that with 1-octanol as sampling phase (Figure 1a). The short equilibration time for uptake into undecane suggests that the diffusion in the aqueous phase is the rate-limiting process. Thus, undecane that possesses much lower partition coefficients for these analytes than 1-octanol required much shorter equilibration time. An organic solvent with a lower partition coefficient for the target analyte is preferred as the sampling phase for reducing the equilibration time, while a solvent with a higher partition coefficient is helpful for obtaining a lower detection limit.

The effect of hollow fiber dimension on the equilibration time was studied by using 1-octanol supported on hollow fiber with different wall thicknesses. The uptake profiles of sampling a solution of OP and NP prepared in a mixture of $1 \mathrm{mM}$ phosphate buffer and $500 \mathrm{mM} \mathrm{NaCl}$ at pH 7.00 (see Figure S3 in Supporting Information) indicate that the equilibration time with X30-240 Celgard is much shorter than that of the 50/280 Accurel PP. Further experiments demonstrated that shorter hollow fiber required relatively shorter equilibration time. When 5 - and 10mm length X30-240 Celgard hollow fiber were used, the equilibration times $\left(t_{95 \%}\right)$ for NP in a mixture of $1 \mathrm{mM}$ buffer and $500 \mathrm{mM}$ $\mathrm{NaCl}$ were 17.4 and $19.5 \mathrm{~h}$, respectively. This is because, when short hollow fiber is used, the chemicals are more easily transport from the two open ends into the lumen center of a hollow fiber. Therefore, the entire surface to volume ratio increased, and thus, the uptake of analytes was more efficient and the equilibration time reduced. In the following studies, a 10-mm X30-240 Celgard hollow fiber supported with 1-octanol was used as sampling phase to obtain a low detection limit. It should be noted, however, 5 mm of X30-240 Celgard hollow fiber membranes (corresponding to $60 \mathrm{~nL}$ of 1-octanol) can be adopted to avoid using a large sample volume and to reduce the equilibration time if the target chemical has sufficiently high $D_{\text {ow }}$.

For all the environmentally relevant conditions as studied in Figure 1, OP and NP prepared in $200 \mathrm{mM}$ phosphate buffer or a mixture of $1 \mathrm{mM}$ phosphate buffer and $500 \mathrm{mM} \mathrm{NaCl}$ required relatively longer time to reach equilibrium. Therefore, these two solutions were adopted to evaluate the equilibration time by sampling with X30-240 Celgard hollow fiber. Table 1 shows the calculated $D_{\text {ow }}, k$, and equilibration time $\left(t_{90 \%}\right.$ and $\left.t_{95 \%}\right)$, based on their uptake profiles fitted with eq 1 . As can be seen, $24 \mathrm{~h}$ is enough to ensure the sampling to reach equilibrium.

It is well known that agitation such as shaking and stirring can decrease the equilibration time, and usually a relatively high stirring rate can more efficiently reduce the equilibration time. In our experiments, a stirrer with five rate levels was adopted. Experiments show that the high stirring rates of levels 4 and 5 were needed to keep the hollow fiber completely immersed in the sample solution, and no significant difference in equilibration time was observed between these two levels. Therefore, the highest stirring speed (level 5) was adopted in the following studies. It was reported that shaking will affect the equilibration times only if diffusion through the aqueous diffusion layer is the rate-limiting process, and which process is rate limiting will highly depend on the chemical. ${ }^{20}$ In field sampling, however, the equilibration time will generally be similar or shorter than under static conditions, and equilibration times determined with static sampling in the laboratory can thus be adopted as conservative estimates for field sampling.

Sample Volume for Avoiding Sample Depletion. Analyte depletion was avoided by using a sufficiently large sample volume. The influence of sample volume was studied with samplers of 10 $\mathrm{mm}$ of X30-240 Celgard hollow fiber that were exposed to various sample volumes (see Figure S4 in Supporting Information). The $C_{\text {octanol }}$ increased with sample volume and was constant at sample volumes above $100 \mathrm{~mL}$. Table 1 also shows that the calculated sample depletion was less than $10 \%$ when $100 \mathrm{~mL}$ of sample was adopted. Thus, $100 \mathrm{~mL}$ of sample solution was sufficient for avoiding depletion for the two studied analytes and was adopted in the following studies. The volume ratio between sample and sampler was $\sim 10^{6}$, which is sufficient for the negligible depletion sampling of analytes with 1-octanol water distribution coefficients

(20) Flynn, G. L.; Yalkowsky, S. H. J. Pharm. Sci. 1972, 61, 838-852. 
of up to $\sim 10^{5}$ if "the extracted amount be kept below $10 \%$ of the freely dissolved amount" was adopted as a criterion of negligible depletion.

Adsorption on the Hollow Fiber Surface. $C_{\text {octanol }}$ was quantified by analyzing the methanol extract of the hollow fiber, which would lead to an overestimation if a significant amount of analyte either would be directly adsorbed to the hollow fiber surface or would be associated with DOM at the hollow fiber surface. To estimate the effect of surface adsorption of DOMbound analyte on the hollow fiber, a solution of $100 \mu \mathrm{g} / \mathrm{L} \mathrm{OP}$ and NP prepared in a mixture of $100 \mathrm{mM}$ phosphate buffer ( $\mathrm{pH} 7.00$ ) and Aldrich humic acid ( $25 \mathrm{mg} / \mathrm{L}$ DOC) was equilibrium sampled by the proposed hollow fiber sampling device with and without dialysis tubing protection. With the protection of the dialysis tubing (MWCO 1000), only the freely dissolved OP and NP can diffuse through the dialysis tubing and be taken up by the hollow fiber sampling device. After 3 days of dialysis, the obtained peak areas with and without dialysis tubing protection were $617 \pm 53$ and $776 \pm 19$ for OP and $164 \pm 10$ and $742 \pm 67$ for NP; whereas after 9 days of dialysis, the peak areas were $576 \pm 22$ and $504 \pm$ 24 for OP and $362 \pm 22$ and $354 \pm 14$ for NP. The good agreement between these two sampling modes after 9 days of dialysis demonstrated that there is no significant adsorption of DOMbound analyte on the surface of the hollow fiber; thus, only the freely dissolved fraction was sensed. With the extension of dialysis time, some precipitation formed in the sample solution, reducing the measured peak area due to the decreasing of $C_{\text {free. }}$.

To test the direct adsorption of analytes on the hollow fiber surface, $10 \mathrm{~mm}$ of X30-240 Celgard hollow fiber membranes without 1-octanol was also applied to sample OP and NP. These fiber membranes contained $14 \%$ of OP and $16 \%$ of NP relative to the membranes with 1-octanol. When the hollow fiber was impregnated with 1-octanol, the pores of the hollow fiber were filled with 1-octanol and adsorption on the pore surface should be much lower. Thus, the direct surface adsorption on the hollow fiber with 1-octanol should be well below $14 \%$ for OP and $16 \%$ for $\mathrm{NP}$, and its effect on the measurement of $C_{\text {octanol }}$ is negligible.

Influence of Environmentally Relevant Parameters on Distribution Coefficient. Although the distribution coefficients $\left(D_{\text {ow }}\right)$ of these two target compounds were reported in some references, the influence of $\mathrm{pH}$, salinity, and buffer capacity on $D_{\text {ow }}$ is not very clear. Therefore, in order to adopt $D_{\text {ow }}$ for calibration, it is necessary to evaluate the effect of environmentally relevant $\mathrm{pH}$, salinity, and buffer capacity.

As shown in Figure 2 a, $D_{\text {ow }}$ increased very slowly with buffer concentration, which might be caused by the salting-out effect. It can be calculated that the relative standard deviation of $D_{\text {ow }}$ in the entire environmentally relevant range of buffer capacity (1$200 \mathrm{mM}$ ) was 9 and 7\% for OP, and NP, respectively. Thus, the overall effect of sample buffer capacity on $D_{\text {ow }}$ was minor and negligible.

The effect of salinity (Figure 2b) was studied by sampling a series of sample solutions prepared in constant buffer concentration $\left(5 \mathrm{mM} \mathrm{NaH}_{2} \mathrm{PO}_{4}\right)$ and acidity $(\mathrm{pH} 7.00)$ but with various salinities (0, 50, 100, 250, 400, 500, $600 \mathrm{mM} \mathrm{NaCl})$. As expected, $\log D_{\text {ow }}$ increased gradually with salinity due to the salting-out effect. The $\log D_{\text {ow }}$ values (with relative standard deviation in parentheses) in the entire environmentally relevant salinity range
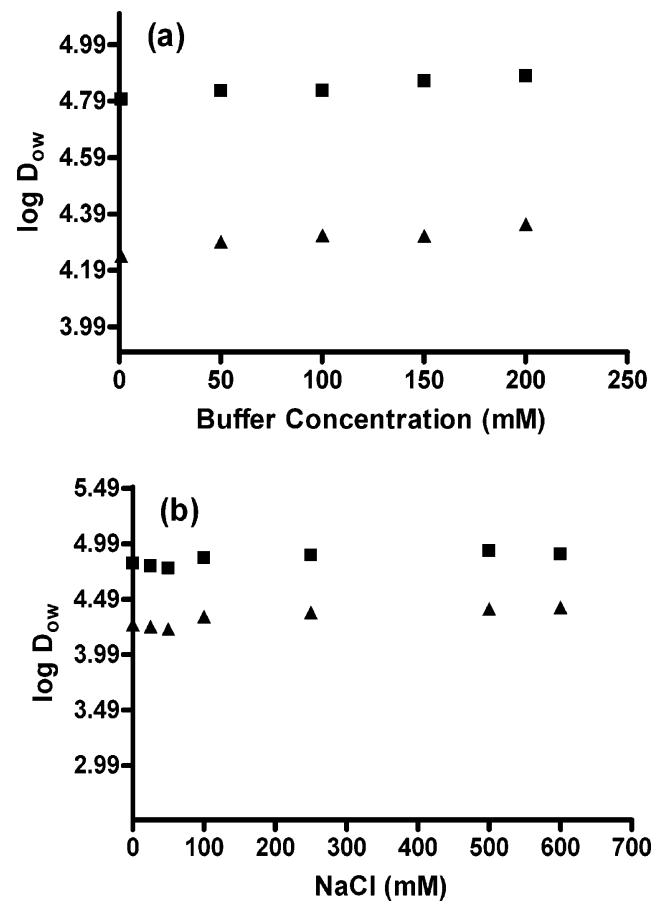

Figure 2. Effect of buffer concentration and salinity on the partition coefficients of OP and NP to 1-octanol. Sampling phase: 1-octanol supported on $10 \mathrm{~mm}$ of $\mathrm{X} 30-240$ Celgard polypropylene hollow fiber; Sampling time: $24 \mathrm{~h}$. $\mathbf{m}, \mathrm{NP}$; $\mathbf{\Lambda}$, OP. Sample solution: (a) $100 \mathrm{~mL}$ of $50 \mu \mathrm{g} / \mathrm{L}$ OP and NP in phosphate buffer (pH 7.00); (b) $100 \mathrm{~mL}$ of 50 $\mu \mathrm{g} / \mathrm{L}$ OP and NP in $5 \mathrm{mM}$ phosphate buffer and various concentrations of $\mathrm{NaCl}(\mathrm{pH} 7.00)$.

(0-600 $\mathrm{mM} \mathrm{NaCl})$, freshwater salinity range $(0-100 \mathrm{mM} \mathrm{NaCl})$, and seawater salinity range $(400-600 \mathrm{mM} \mathrm{NaCl})$ were $4.32(18 \%)$, $4.24(4 \%)$, and $4.39(5 \%)$ for OP and $4.85(13 \%), 4.79(5 \%)$, and 4.90 (5\%) for NP, respectively. These results indicate that, if accurate measurement was required, the influence of salinity on $D_{\text {ow }}$ should be calibrated. The relative standard deviation can be controlled within $7 \%$ by adopting $D_{\text {ow }}$ measured using respective solutions without $\mathrm{NaCl}$ and with $500 \mathrm{mM} \mathrm{NaCl}$ for calibration freshwater and seawater samples, respectively. For rough estimation, however, it is unnecessary to calibrate the effect of salinity.

It is well known that $\mathrm{pH}$ can significantly influence the partitioning of ionizable hydrophobic chemicals to 1-octanol. ${ }^{21}$ Figure 3 shows the effect of $\mathrm{pH}$ on the $D_{\text {ow }}$ of OP and NP. The $D_{\text {ow }}$ values keep constant within the environmentally relevant $\mathrm{pH}$ range (5.0-8.5) and decrease with increasing $\mathrm{pH}$ in the range of $10-12$. This result can be explained by the $\mathrm{p} K_{a}$ values of these compounds and the lower distribution coefficients in 1-octanol when part of these compounds are ionized. It was reported ${ }^{22,23}$ that OP and NP are very weak acids with $\mathrm{p} K_{\mathrm{a}}=9.5-10.7$; thus, they will be found mainly in their molecular form at $\mathrm{pH}$ values below 8.5 and deprotonated form at over 10.7. Therefore, their $D_{\text {ow }}$ should be constant within the environmentally relevant $\mathrm{pH}$ range (5.0-8.5) and decrease with increasing $\mathrm{pH}$ at $\mathrm{pH}$ above 8.5 .

(21) Escher, B. I.; Schwarzenbach, R. P. Environ. Sci. Technol. 1996, 30, 260270.

(22) Motoyama, A.; Suzuki, A.; Shirota, O.; Namba, R. Rapid Commun. Mass Spectrom. 1999, 13, 2204-2208.

(23) Lee, H. B.; Peart, T. E. Water Qual. Res. J. Can. 2002, 37, 681-696. 


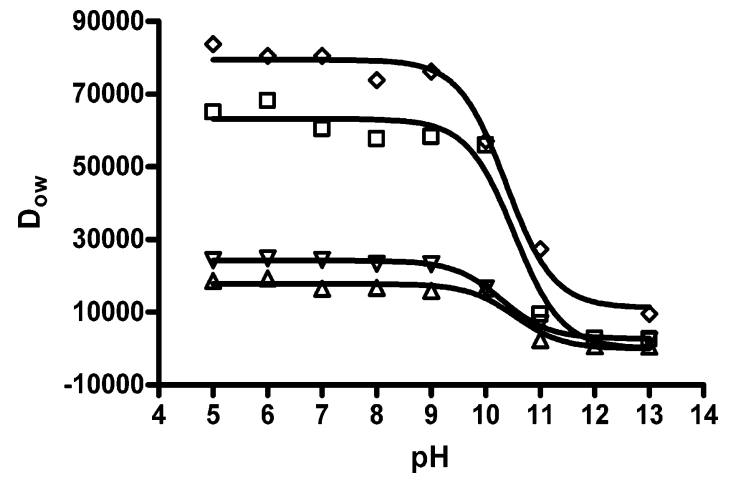

Figure 3. Effect of sample $\mathrm{pH}$ on the partition coefficients of $\mathrm{OP}$ and NP to 1-octanol. The lines represent the fit of eq 6 to the data. Sample solution: $100 \mathrm{~mL}$ of $50 \mu \mathrm{g} / \mathrm{L}$ OP and NP. Sampling phase: 1-octanol supported on $10 \mathrm{~mm}$ of X30-240 Celgard polypropylene hollow fiber. Sampling time: $24 \mathrm{~h} . \diamond$, NP in $100 \mathrm{mM}$ phosphate buffer; $\square, \mathrm{NP}$ in $10 \mathrm{mM}$ phosphate buffer; $\nabla, \mathrm{OP}$ in $100 \mathrm{mM}$ phosphate buffer; $\triangle$, OP in $10 \mathrm{mM}$ phosphate buffer.

\section{Table 2. Results of Nonlinear Regression of $D_{\text {ow }}$ (mean \pm s) and Regression Coefficient $\left(R^{2}\right)$ of OP and NP Based on Data at Different pH Values (pH 5-12) and Phosphate Buffer Concentrations}

\begin{tabular}{llll} 
& \multicolumn{2}{c}{$\log D_{\mathrm{ow}}$} & \\
\cline { 2 - 3 } & \multicolumn{1}{c}{$\mathrm{HA}^{a}$} & $\mathrm{~A}^{b}$ & \\
$10 \mathrm{mM}$ phosphate buffer & & & \\
OP & $4.25 \pm 0.20$ & -7.00 & 0.96 \\
NP & $4.80 \pm 0.18$ & -7.15 & 0.97 \\
$100 \mathrm{mM}$ phosphate buffer & & & \\
OP & $4.38 \pm 0.05$ & $3.43 \pm 0.68$ & 0.99 \\
NP & $4.90 \pm 0.10$ & $4.05 \pm 1.20$ & 0.99
\end{tabular}

${ }^{a} \mathrm{HA}$, the molecular form of OP and NP. ${ }^{b} \mathrm{~A}$, the deprotonated form of OP and NP.

Assuming both the molecular form (HA) and deprotonated form (A) of OP and NP can partition into 1-octanol, the $D_{\text {ow }}$ at different $\mathrm{pH}$ was fitted to the following equation ${ }^{19}$

$$
D_{\text {ow }}=\left(D_{\mathrm{HA}}+D_{\mathrm{A}} \times 10^{\mathrm{pH}-\mathrm{p} K \mathrm{a}}\right) /\left(1+10^{\mathrm{pH}-\mathrm{p} K \mathrm{a}}\right)
$$

As shown in Figure 3, the experimental results fitted well with eq 6 with correlation coefficients $R^{2} \geq 0.96$. The nonlinear regression values of $D_{\mathrm{ow}}$ represented in Table 2 demonstrated their good agreement with the values $\left(\log K_{\text {ow }}=4.12\right.$ for OP, and $4.2 \sim 4.48$ for NP) reported in refs 22 and 23 . The relatively higher $D_{\text {ow }}$ values of OP and NP in $100 \mathrm{mM}$ buffer than that in $10 \mathrm{mM}$ buffer is due to the salting-out effect.

Analytical Performance and $\boldsymbol{D}_{\text {ow }}$ Determination. The $D_{\text {ow }}$ values and analytical performance characteristics were determined with synthetic standard solutions that can represent most environmental relevant conditions, i.e., various concentrations $(0.2-$ $250 \mu \mathrm{g} / \mathrm{L}$ ) of analytes spiked in solution of $100 \mathrm{mM}$ phosphate buffer ( $\mathrm{pH}$ 7.00). Results indicate that this proposed method possesses good linearity $\left(R^{2}=0.9973-0.9975\right)$, excellent precisions at $5 \mu \mathrm{g} / \mathrm{L}$ level (RSD $=4-5 \%, n=3$ ), and low detection limits $(0.06-0.1 \mu \mathrm{g} / \mathrm{L})$. The measured $\log D_{\text {ow }}$ was independent of the chemical concentration $(4.32 \pm 0.06$ for OP, and $4.79 \pm$ 0.02 for NP. See Table S2 in Supporting Information) and agreed well with the reported $\log K_{\mathrm{ow}}$ values (4.12 for OP, and 4.2-4.48 for NP) in refs 22 and 23 . The probable reasons for the slightly higher measured than reported $\log D_{\mathrm{ow}}$ values are as follows: (i) instead of individual solutions, a mixture of OP and BPA was used; (ii) the aqueous phase was $100 \mathrm{mM}$ phosphate buffer instead of reagent water.

Effect of DOM on Free Concentration and $D_{\text {Doc }}$ Determination. Synthetic sample solutions (pH 7.00) containing $100 \mathrm{mM}$ $\mathrm{NaH}_{2} \mathrm{PO}_{4}$ and certain concentrations of DOM (humic acids and BSA) were used to study the effect of DOM on the $C_{\text {free }}$ of OP and NP. Before sampling, these solutions were spiked with OP and NP and shaken for $1 \mathrm{~h}$ to ensure equilibrium between the chemicals and DOM. The decrease in the free concentration after the addition of DOM was measured by this proposed sampling procedure.

The free fraction (defined as the ratio between the free and total concentrations) at different DOM concentrations (normalized to the carbon content, DOC) was fitted to the following equation adapted from Kukkonen et al. ${ }^{24}$

$$
f=1 /\left(1+D_{\text {DOC }} C_{\text {DOC }}\right)
$$

where $f$ is the free fraction, $D_{\mathrm{DOC}}$ is the distribution coefficient between DOC and water of the studied chemical, and $C_{\mathrm{DOC}}$ is the aqueous concentration of DOC.

Results shown in Figure 4 indicate that the $f$ decreased with the increase of added DOC as expected. However, the $f-C_{\mathrm{DOC}}$ profiles cannot be fitted by eq 7 except for NP, which at low concentrations of BSA $(0-0.0025 \mathrm{~kg} / \mathrm{L})$ can be fitted with a correlation coefficient of $R^{2}=0.86$. The experiments with dialysis membrane-protected sampling demonstrated that there is no significant adsorption of DOM-bound analyte on the surface of the hollow fiber. The disagreement between free fraction measurement and model prediction should therefore not be attributed to the fouling of the membrane with humic acids. Thus, it might be suggested that the interaction of OP and NP with DOC is not just a simple and linear partitioning process. In our experiment, $\sim 74 \%$ of NP was presented as an associate form in an Aldrich humic acid solution with $50 \mathrm{mg} / \mathrm{L} \mathrm{DOC}$. This result is close to that $(73 \%$ in $330 \mathrm{mg} / \mathrm{L} \mathrm{DOC}$ and $87 \%$ in $1000 \mathrm{mg} / \mathrm{L} \mathrm{DOC})$ reported in the literature. ${ }^{18}$ It should be noted that, when Acros humic acid was added, the free fractions at $1-2.5 \mathrm{mg} / \mathrm{L}$ DOC were lower than that at $5 \mathrm{mg} / \mathrm{L} \mathrm{DOC}$ for both OP and NP. This unusual behavior of Acros humic acid was also observed in a previous study ${ }^{25}$ by using SPME for measuring the free concentration of bisphenol A, but the reason is not clear yet. As shown in Table 3, for both OP and NP, the $D_{\mathrm{DOC}}$ values decreased gradually with the increase of DOC concentration, and $D_{\mathrm{DOC}}$ values are in the same magnitude as $K_{\mathrm{ow}}$. The measured $D_{\mathrm{DOC}}$ values also agreed with reported apparent partition coefficients to organic carbon (log $K_{0 c}$ ) for particles in river water and effluent wastewater (5.22 \pm 0.38 for NP, $4.65 \pm 0.42$ for $\mathrm{OP})^{16}$ and terrestrial soils (3.97 for NP). ${ }^{17}$

Determination of $\boldsymbol{C}_{\text {free }}$ in Water Samples. The proposed procedure was applied to determine the free concentrations of

(24) Kukkonen, J.; Oikari, A.; Johnsen, S.; Gjessing, E. Sci. Total Environ. 1989 79, 197-207.

(25) Hu, X.-L.; Peng, J.-F.; Liu, J.-F.; Jiang, G.-B. Jönsson, J. Å. Chemosphere, in press. 

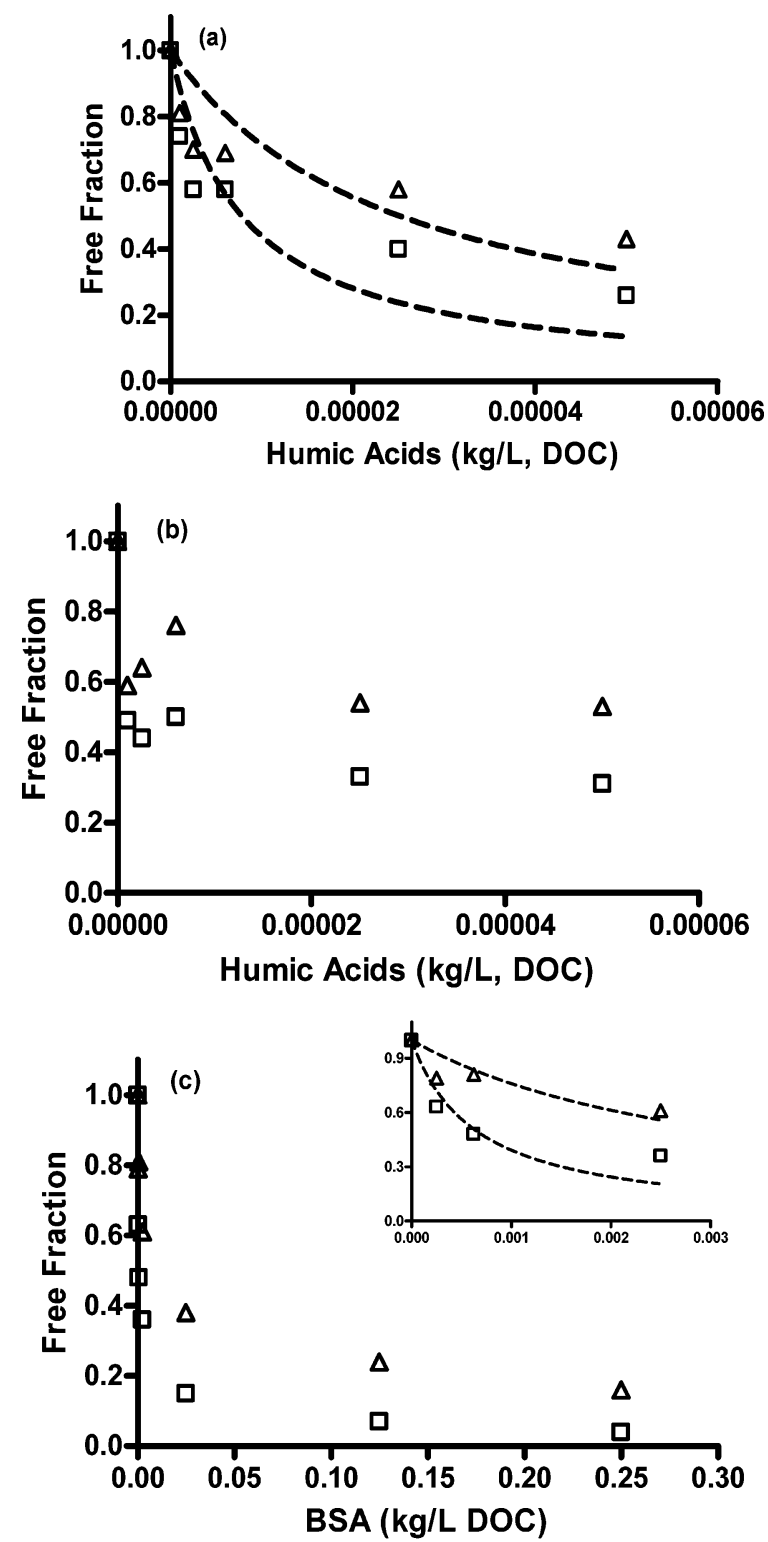

Figure 4. Effect of DOC concentration on the free fraction of OP and NP. The lines represent the fit of eq 7 to the data. Sample solution: $100 \mathrm{~mL}$ of $50 \mu \mathrm{g} / \mathrm{L}$ OP and NP in $100 \mathrm{mM}$ phosphate buffer and different concentration of humic acid and BSA, pH 7.00. Sampling phase: 1-octanol supported on $10 \mathrm{~mm}$ of X30-240 Celgard polypropylene hollow fiber. Sampling time: $24 \mathrm{~h}$. $\square$, NP; $\triangle$, OP. (a) Aldrich humic acid; (b) Acros humic acid; (c) BSA.

OP and NP in tap water, river water, and municipal sewage effluent water samples. To determine the free concentration after spiking the studied chemicals, samples were spiked with 5 or $50 \mu \mathrm{g} / \mathrm{L}$ standards. Results show that native OP and NP were under the detection limits in all the studied samples and that $C_{\text {free }}$ of spiked analytes roughly decreased with the increase of DOC concentration even though the matrixes were different in the studied samples (Table 4).

\section{CONCLUSIONS AND PERSPECTIVES}

Submicroliter volumes of organic solvent were easily immobilized on a porous hollow fiber membrane and then applied for diffusive equilibrium sampling. This TLFE technique can be directed at the determination of freely dissolved analyte concentra-
Table 3. Measured log Dooc of OP and NP in Aldrich Humic Acid, Acros Humic Acid, and BSA Solutions

\begin{tabular}{|c|c|c|c|c|c|c|}
\hline \multirow{2}{*}{$\begin{array}{c}\text { DOC concn } \\
\left(\times 10^{-6} \mathrm{~kg} / \mathrm{L}\right)\end{array}$} & \multicolumn{2}{|c|}{$\begin{array}{c}\text { Aldrich } \\
\text { humic acid }\end{array}$} & \multicolumn{2}{|c|}{$\begin{array}{c}\text { Acros } \\
\text { humic acid }\end{array}$} & \multicolumn{2}{|c|}{ BSA } \\
\hline & OP & NP & OP & NP & OP & NP \\
\hline 0.25 & & & & & 6.02 & 6.37 \\
\hline 0.62 & & & & & 5.58 & 6.24 \\
\hline 1 & 5.37 & 5.55 & 5.84 & 6.02 & & \\
\hline 2.5 & 5.24 & 5.46 & 5.35 & 5.70 & 5.41 & 5.85 \\
\hline 5 & 4.96 & 5.16 & 4.79 & 5.29 & & \\
\hline 25 & 4.47 & 4.77 & 4.54 & 4.9 & 4.81 & 5.34 \\
\hline 50 & 4.43 & 4.76 & 4.25 & 4.65 & & \\
\hline 125 & & & & & 4.40 & 5.00 \\
\hline 250 & & & & & 4.35 & 4.92 \\
\hline mean \pm sd & $\begin{array}{l}4.89 \\
\pm 0.43\end{array}$ & $\begin{array}{l}5.14 \\
\pm 0.37\end{array}$ & $\begin{array}{l}4.96 \\
\pm 0.64\end{array}$ & $\begin{array}{l}5.31 \\
\pm 0.56\end{array}$ & $\begin{array}{l}5.10 \\
\pm 0.68\end{array}$ & $\begin{array}{l}5.62 \\
\pm 0.6\end{array}$ \\
\hline
\end{tabular}

\section{Table 4. Free Concentration ( $\left.C_{\text {free }}\right)$ of OP and NP $(\mu \mathrm{g} / \mathrm{L}$, Mean of 3 Measurements) in Water Samples Measured by the Proposed Method}

\begin{tabular}{|c|c|c|c|c|c|}
\hline \multirow[b]{2}{*}{ sample } & \multirow[b]{2}{*}{$\mathrm{pH}$} & \multirow{2}{*}{$\begin{array}{c}\text { DOC } \\
(\mathrm{mg} / \mathrm{L})\end{array}$} & \multirow{2}{*}{$\begin{array}{l}\text { spiked } \\
\mu \mathrm{g} / \mathrm{L})\end{array}$} & \multicolumn{2}{|c|}{$C_{\text {free }}(\mu \mathrm{g} / \mathrm{L})$} \\
\hline & & & & OP & $\mathrm{NP}$ \\
\hline \multirow[t]{2}{*}{ wastewater } & 7.78 & 9.5 & 0 & $\mathrm{nd}^{a}$ & nd \\
\hline & & & 5 & $3.44 \pm 0.07$ & $2.14 \pm 0.15$ \\
\hline \multirow{3}{*}{$\begin{array}{l}\text { municipal sewage } \\
\text { effluent } 1\end{array}$} & 7.28 & 11.7 & 0 & & \\
\hline & & & 5 & $2.22 \pm 0.11$ & $1.39 \pm 0.08$ \\
\hline & & & 50 & $19.0 \pm 1.7$ & $11.7 \pm 1.6$ \\
\hline \multirow{2}{*}{$\begin{array}{l}\text { municipal sewage } \\
\text { effluent } 2\end{array}$} & 7.44 & 13.2 & 0 & & \\
\hline & & & $\begin{array}{l}5 \\
50\end{array}$ & $\begin{array}{l}2.37 \pm 0.07 \\
20.8 \pm 1.7\end{array}$ & $\begin{array}{l}1.69 \pm 0.10 \\
16.3 \pm 1.1\end{array}$ \\
\hline \multirow[t]{3}{*}{ river water } & 8.20 & 3.5 & 0 & & nd \\
\hline & & & 5 & $2.70 \pm 0.05$ & $2.95 \pm 0.06$ \\
\hline & 776 & 25 & 50 & $47.2 \pm 2.4$ & $\begin{array}{l}42.6 \pm 2.9 \\
\text { nd }\end{array}$ \\
\hline \multirow{2}{*}{ tap water } & 1.10 & 2.0 & 5 & $3.12 \pm 0.10$ & $4.42 \pm 0.22$ \\
\hline & & & 50 & $49.1 \pm 1.0$ & $45.7 \pm 0.9$ \\
\hline
\end{tabular}

tions in environmental water samples, at the determination of 1-octanol to water partition coefficients, or at studying binding to DOC. This sampling device is very inexpensive, easy to prepare and disposable, and needs relatively small sample volume to avoid depletion even for compounds with large $K_{\text {ow }}$ values. The equilibration time is short as the thin hollow fiber was adopted as supporter, and liquid 1-octanol was adopted as sampling phase in which compounds had high diffusion rate in comparison with using solid phase/viscous liquid as sampling phase. Further, the widely available $K_{\mathrm{ow}}$ values of most compounds make it a very good reference for evaluating the reliability of the measured $D_{\text {ow }}$ that was used for calibrating the $C_{\text {free}}$, or the $K_{\text {ow }}$ can be adopted directly to estimate the $C_{\text {free }}$. Another advantage of using 1-octanol as the sampling phase is that the measured $C_{\text {octanol }}$ is compatible with many environmental risk assessment and fate models, in which $K_{\mathrm{ow}}$ was adopted to estimate bioconcentration factors and environmental phase partitioning.

In this present procedure, the accurate determination of $C_{\text {free }}$ depends on the accurate determination of $D_{\text {ow }}$, while $D_{\text {ow }}$ relies on accurate measuring of the small volume of 1-octanol supported on the hollow fiber membrane. $D_{\mathrm{ow}}$ can be calibrated by mimicking experiments under environmentally relevant conditions. For a rough estimation, however, $K_{\mathrm{ow}}$ values reported in the literature 
might be used directly. The good agreement between our measured $D_{\text {ow }}$ with reported values demonstrated that our proposed method for measuring the small volume of organic solvent supported on the hollow fiber membrane is reliable, and this proposed sampling device has potential applicability for measuring the $K_{\mathrm{ow}}$ values of chemicals, as well as the partition coefficients of chemicals to environmental matrix components such as $D_{\text {Doc. }}$.

Most sampling and extraction techniques that are used in the laboratory can hardly be applied in the field, since they require a defined sample volume or highly controlled and standardized sampling conditions. The proposed TLFE technique requires only that the thin liquid film is brought into equilibrium with a sufficiently large "sample volume", and this makes the TLFE format very suited for field sampling. However, the application of TLFE for field sampling requires further research to demonstrate the stability of the liquid membrane under field conditions and to determine the equilibration time at real environmental conditions as it is influenced by some factors such as temperature and flow of water. The equilibrium sampling into thin liquid films has many similarities with other equilibrium sampling devices, especially SPME, ${ }^{12}$ which also can be directed at the measurement of the chemical activity or the fugacity of an analyte. ${ }^{26}$ Impregnated hollow fiber seems an attractive format to be applied in equilibrium

(26) Reichenberg, R.; Mayer, P. Environ. Toxicol. Chem. 2006, 25, 1239-1245. field sampling of mainly hydrophobic chemicals with $\log K_{\text {ow }} \geq$ 2 , since they combine low cost, simplicity, and a high surface to volume ratio. For sampling chemicals with lower $K_{\text {ow }}$ values, using organic solvents filled in the lumen of a hollow fiber might be more suitable.

\section{ACKNOWLEDGMENT}

This work was jointly supported by the National Natural Science Foundation of China (20477052, 20577059) and the National Basic Research Program of China (2003CB415001). J.-F.L. acknowledges the financial support by the Foundation for Strategic Environmental Research (MISTRA), Sweden.

\section{SUPPORTING INFORMATION AVAILABLE}

Figures showing the optimization of desorption time, the effect of organic solvent and hollow fiber dimensions on the uptake profiles of analytes, and the sample volume required to avoid sample depletion, as well as tables listing the measured $\log D_{\text {ow }}$, $\log D_{\mathrm{DoC}}$ values at various analytes and DOC concentrations. This material is available free of charge via the Internet at http:// pubs.acs.org.

Received for review August 15, 2006. Accepted October 4, 2006.

AC0615145 